\title{
Geophysical images of the deep crust: the lapetus suture
}

D. Beamish and D.K. Smythe

British Geological Survey, Murchison House, West Mains Road, Edinburgh EH9 3LA

Beamish, D. \& Smythe, D.K. 1986. Geophysical images of the deep crust: the lapetus suture. Journal of the Geological Society, London, Vol. 143, 1986, pp. 489-497

DOI 10.1144/gsjgs.143.3.0489

\section{Abstract}

The lapetus suture, arguably the most fundamental lineament of British and Irish structure, has been previously identified on the BIRPS WINCH deep seismic reflection profiles offshore as a NW-dipping feature. New depth-migrated interpretations of these and other reflection data show good correlation of structure for $100 \mathrm{~km}$ along strike in the northern Irish Sea towards magnetotelluric stations onshore in the north of England and Southern Uplands of Scotland. Three different methods of inverting data from these sites all reveal a thin NW-dipping slab of high conductivity. A contour map of the suture trace, dipping at $15-25^{\circ} \mathrm{NW}$, can be constructed down to and through the Moho at $28 \mathrm{~km}$ depth. This map suggests crustal stretching below the Solway Basin. The ?mylonitic suture zone is characterized by good seismic reflection layering, high conductivity (presumably fluidproduced), and a steep increase of P-wave velocity over the few kilometres of its width. Crustal refraction experiments LISPB and CSSP provide useful velocities, but locally misleading structure, so that the combination of the seismic reflection and geoelectric methods may be the most powerful means of determining deep crustal structure with a good degree of both vertical and lateral resolution. 
Few geophysical sounding techniques use energy sources sufficiently powerful to probe the middle and lower crust. Two of the techniques, which we consider here, are deep seismic reflection profiling (artificial acoustic wave propagation) and magnetotelluric deep sounding (natural electro- magnetic wave diffusion). The physical basis and information content of the two techniques are very different. In the former case, acoustic boundaries are imaged with a vertical spatial resolution on the order of 100-300 m, and a horizontal spatial resolution of perhaps an order of magnitude more, whereas in the latter case, high contrast electrical conductivity variations are imaged with much less spatial resolution. The two techniques essentially sound two distinct material properties of the crust at widely differing spatial scales. These differences therefore lead to independent images of structure deep within the crust. Since the number of constraints that can be applied to control the modelling and to aid the interpretation of results from each technique is severely limited at such depths, an obvious question to ask is-to what extent can the results of the two techniques be usefully combined? Our purpose here is to present and compare recent results obtained by the two techniques across an area where deep crustal structural models are required in order to reconstruct the geometry of the lapetus suture, which is arguably the most fundamental lineament in British Caledonian geology.

A controlled source electromagnetic sounding experiment has been linked to COCORP deep seismic reflection profiling in the South Appalachians (Thompson et al. 1983), but we believe that this is the first attempt to correlate in detail the results of the more common natural electromagnetic sounding technique with deep seismic reflection data. Although the two studies described here are separated by some $180 \mathrm{~km}$, along the strike of Caledonian structure, we show that continuity of upper and mid crustal structure appears to be good enough for the correlation to be possible. The problem remains, however, of exactly what physical properties and rock structure are being correlated.

\section{Previous work}

The lapetus suture is defined as the zone separating continental crustal blocks which were formerly on opposing margins of the early Palaeozoic 'proto Atlantic' ocean (Wilson 1966). Closure of the ocean, nowadays called the lapetus ocean, was effected by Benioff-type subduction of oceanic lithosphere below the northern continental margin, and possibly also below the southern margin, depending upon the conceptual model adopted. Moseley (1977), reviewing the variety of conceptual models, pointed out that the results of the lithospheric refraction profile LISPB (Fig. 1), by then becoming available (Bamford et al. 1976, 1978) precluded the existence of any significant remnant of Palaeozoic oceanic crust below northern England. Nevertheless, geologists were able to map the surface expression of the suture, as defined by 'Pacific' versus 'Atlantic' (or 'Baltic') fauna! provinces in the Cambrian and Ordovician of Britain and Ireland, and as defined on structural grounds (Phillips et al. 1976). This line, as it affects the Lower Palaeozoic sedimentary prisms lying upon, or obducted over, continental crust, runs NE from Salterstown, on the eastern Irish coast, across the northern Irish Sea, and is interpolated through the Solway Firth and below the Northumberland Trough. Figure 1 shows the outcrops of the rocks that constrain its position. Note, however, that the line defined in this way is only an approximate guide to the location of the suture at depth between the two juxtaposed continental lithospheric plates, and provides no direct clue to the nature or orientation of the suture below (or even within) the Lower Palaeozoic. At depth the models rely, necessarily, on idealized cartoons of island-arc type subduction 
and collision. A common feature of these models, despite major differences in interpretation of the upper crust, is the expectation that the suture at depth should be a northerly-dipping feature, with north of England crust thrust below the Southern Uplands of Scotland and Northern Ireland. The question is, how can such a 'feature' be imaged geophysically?

\section{Deep seismic reflection and seismic refraction profiles}

In 1982 the BIRPS WINCH deep seismic reflection profiles were acquired along and across the Caledonian strike in the region (Fig. 1), with the aim, in part, of addressing this problem. The lapetus suture is identified on WINCH-2 as the expected northerly-dipping boundary between a crust to the south with good lower crustal reflections and reasonably well-imaged Moho, and crust to the north where the crustal reflectors are rare or absent (Brewer et al. 1983). The relevant portion of data has been reproduced as an unmigrated stack section by Hall et al. (1984, fig. 5), who have also interpreted the Southern Uplands region above the suture by a 'zig-zag' crustal shortening model. Figure 2 shows a squash-plotted depth-migrated line drawing of WINCH-2E, and the neighbouring ESW segment, WINCH-3. Migration of the standard line drawing (Brewer et al. 1983) in the depth domain was done using the one-dimensional velocity function shown in Fig. 2. These and other line drawing migrations were made using a ray-tracing program written in Fortran by Bernard Raynaud of Cambridge University.

Can the WINCH deep reflection data be related any more closely to the land geology? In particular, can they be tied in along strike to the three geoelectric profile stations in the north of England and Southern Uplands, some $200 \mathrm{~km}$ distant? There are no other reflection data west of the Isle of Man available to help tie the relevant reflectors across to Ireland, but there are many commercial multichannel profiles in the North Channel, Solway Firth and eastern Irish Sea. Unfortunately most of these data are designed for relatively high resolution mapping of the sediments, and have used short recording times (4 s), small sources, and short receiver arrays. However, some surveys have been shot to $6 \mathrm{~s}$, with suitable size of source and receiver arrays. We have mapped the deep information on these data in the Solway Firth region. Depth migrated line drawings of two of these Jines are shown in Fig. 3, together with a part of WINCH-2E, and all three are shown at a natural scale (no vertical exaggeration). Three zones of reflectors can be mapped:

(1) the Upper Palaeozoic-Mesozoic sedimentary basins (not discussed further here) below which there is

(2) a characteristically 'blank', or acoustically transparent zone, which can be tied into sea-bed outcrop of the Silurian accretionary prism of SW Scotland (Leggett et al. 1979), and

(3) seismically reflective crust beneath.

The reflective layering can be mapped as several regions (see Fig. 1) as follows:

(1) flat layering below 3-3.5 s (c. 8-15 km depth) between the Isle of Man and the Lake District,

(2) a band of $\mathrm{N}$ to NW-dipping reflectors below 3.5-4 s (10-15 km depth) which can be extrapolated westwards from the northern tip of the Isle of Man to link to the similar zone of WINCH-2E, between 50-70 km from the SE end of the line (Fig. 3a), and 
(3) a band of southerly dipping reflectors near the coast of southern Scotland. These reflectors appear to terminate in the blank zone to the south, but their continuation to the north is unknown due to lack of data.

Note that although the southerly-dipping reflectors are recorded offshore, they actually originate from structure which is partly below the land outcrop of the Silurian, because of the strong southerly dip. This band can also be extrapolated west along strike, to link to the rather vague group of similarly south-dipping reflectors at $12-15 \mathrm{~km}$ depth on WINCH-2E. Line-2 (Fig. 3c) demonstrates that the zone is not simply a coastal artefact feature, as might be suspected of Line- 1 in isolation, because the NW end of Line-2 ends in the middle of a bay, some $5 \mathrm{~km}$ from the coast. If the 'deep' reflectors were, in fact, from out-of plane, 'side-swipe', for example side reflections from the surf zone, they would have arrived at later times (greater apparent depths) than those on Line-1. However, as they come in earlier than on Line-1, this lends confidence to the mapping and interpretation of the south-dipping zone of reflectors as a significant, real, group of intra-crustal reflectors.

Like WINCH, the Caledonian suture seismic project (CSSP) was also observed in 1982 (Fig. 1) and preliminary results from this crustal refraction experiment have now been published (Bott et al. 1985). As the line follows the expected surface position of the suture from Ireland to the North Sea, it is not clear how, in isolation, any results from this experiment are supposed to elucidate the crustal structure of the suture itself. A Moho P-wave phase with a high apparent velocity of $8.3 \mathrm{~km}$ s-1 was observed at north of England stations from the shots in the Irish Sea (Fig. 1). This high upper mantle velocity is considered by Bott et al. (1985) to be due to systematic variations in thickness of the sedimentary cover of the Solway Firth region. However, it is also apparent from Fig. 1 that if the mapping of the northerly-dipping zone of reflectors is correct, then the line of CSSP shots running SW, north of the Isle of Man, is moving obliquely up the dip of the suture. This unfortunate positioning will complicate future interpretations of crustal structure to be derived from CSSP.

The preliminary seismic mapping described above shows that the mid-crustal reflection structures interpreted from the WINCH data have a general trend very similar to that of the Caledonian rocks as mapped at the surface, and that the lapetus suture, as identified on WINCH-2E, can be extrapolated with confidence at least halfway towards the geoelectric sites. This leads us to a discussion of the crustal structure interpreted from these sites.

\section{The geoelectric profile}

The data set we now consider is provided by 5-component magnetotelluric (MT) observations obtained by us in the region of the Northumberland Trough (Fig. 1). The processing and analysis of these data have been described by Beamish (1986a). In general the results, consisting of tensor frequency response functions, contain contributions from 1-, 2- and 3-dimensional structural components. Vertical geoelectric profiles can be obtained directly only if a set of prescribed dimensional indicators display the required degree of 1-dimensional behaviour across a certain frequency interval. This is the case for the response data at locations MT1, MT2 and MT3 (Fig. 1) over the interval 37 to 400 seconds (Beamish 1986b). The deep crustal geoelectric profiles recovered from these data (Beamish 1986a) reveal a single highly conducting layer at mid to lower crustal depths. A recent application of a new scheme of 1-dimensional inversion to these data has 
provided well-ordered bounds on the vertical structure that can be deduced. We now consider how such profiles have been obtained, and why they should be regarded as blurred images with a limited resolution.

Table 1. Parameters of the Highly Conducting Layer (HCL) determined by three inversion schemes at three sites $M T$ l (Craik), MT2 (Keilder) and MT3 (Wark) Note. Solutions 1 and 2 refer to the results obtained by Beamish (1986a). The solution $D+$ refers to the results of the present study. This solution provides no estimate of the layer thickness.

\begin{tabular}{lcccc}
\hline & $\begin{array}{c}\text { Depth } \\
\mathrm{d}(\mathrm{km})\end{array}$ & $\begin{array}{c}\text { Thickness } \\
\mathrm{t}(\mathrm{km})\end{array}$ & $\begin{array}{c}\text { Conductance } \\
\text { a.t (Siemens) }\end{array}$ & Chi-square \\
\hline MT1 1 & 26.10 & 5.40 & 489.57 & 20.0 \\
MT1 2 & 28.08 & 3.95 & 482.62 & 20.9 \\
MT1 D+ & 29.1 & ----- & 648.87 & 9.6 \\
& & & 626.60 & 22.4 \\
MT2 1 & 15.70 & 4.80 & 645.14 & 23.0 \\
MT2 2 & 14.89 & 7.96 & 774.14 & 12.7 \\
MT2 D+ & 18.38 & ---- & 793.81 & 30.9 \\
MT3 1 & 7.80 & 7.70 & 750.63 & 22.3 \\
MT3 2 & 8.39 & 3.04 & 838.10 & 11.0 \\
MT3 D+ & 10.67 & ----- & \multicolumn{2}{c}{}
\end{tabular}

When a statistical confidence level can be prescribed for geophysical results, it is apparent that limits are set with regard to uniqueness and resolution (Backus \& Gilbert 1968, 1970). For practical MT data an assessment of the range of model variability must be made before the features detected in a particular model can be accepted as a representative image of the real Earth. The one-dimensional MT inverse problem is non-linear, and many model construction algorithms depend upon a linearization of the problem. Such algorithms possess an inherent weakness in their ability to provide systematic inferences about real Earth structure. The difficulties of model construction can be overcome using the fully non-linear solution to the MT problem given by Parker $(1980,1983)$ and Parker \& Whaler (1981). The solutions provide three classes of model, of which we consider here only two, referred to as $\mathrm{D}+$ and $\mathrm{H}+$.

The solutions acknowledge the fact that the data possess errors; the acceptability of any particular model is measured by a statistical misfit referred to as chi-square (X2). The theory presented by Parker (1980) establishes the fact that the optimum (best-fit) model we can generate from the data is a delta-function ( $D+$ ) model. This model consists of a finite number of delta-functions (layers of zero thickness but finite conductance), separated by perfect insulators. Such an image is regarded as mathematically pathological and therefore non-physical. The best-fit $(D+)$ solutions obtained for the three data sets, compared with the equivalent parameters of the highly conducting layer (HCL) obtained by the two previous inversion schemes, are shown in Table 1. The conductance of the $\mathrm{HCL}$ is defined by the product of its conductivity and its thickness. We get very good agreement between the three sets of conductance values obtained. The previous results (solutions 1 and 2; Beamish 1986a) can be understood to be mathematical attempts to obtain a best-fit solution using alternative model construction schemes. As the values of chi-square indicate, the two attempts approach the optimum (D+) solution but inevitably stop short. For the present data the expected value of $X 2$ is 16 ; the $D+$ models therefore 'overfit' the data while the previous inversion schemes 'underfit' the data. In order to provide a more realistic image of conductivity structure we are forced to accept a higher level of misfit than the minimum. For our data a level of $\chi^{2}>27$ can be considered unacceptable at the $95 \%$ confidence level. 
The $\mathrm{H}+$ solutions provided by Parker (1980) offer a means of constructing layered models with a $\chi^{2}$ misfit that can be made as close as possible to the minimum value. A systematic family of $\mathrm{H}+$ models possessing two distinct end members can thus be generated. The first such bound is provided by the $D+$ solution. The second bound is provided by the $H+$ model possessing $\chi 2=27$. In theory the $\mathrm{H}+$ intermediate solutions could be oscillatory and could generate end members with widely different numbers of conducting layers. In the case of the present data all the acceptable $\mathrm{H}+$ solutions are particularly simple and give rise to a single crustal conducting layer. The parameters of the $\mathrm{HCL}$ we wish to resolve are the depth to its upper surface (d), its thickness (t) and conductivity ( $\sigma$ ) or resistivity $(\rho=1 / \sigma)$. The family of $\mathrm{H}+$ solutions produce bounded intervals in $\mathrm{d}$ and $\rho$, at the three locations, as shown in Fig. 4 . Starting at the $95 \%$ bound and moving along the curve for a particular location provides acceptable estimates for the parameter pair $(d, \rho)$ at decreasing levels of misfit. Maximum resistivities (minimum depths) are found at the $95 \%$ bound, while minimum resistivities (maximum depths) are found at the $D+$ bound. The statistically acceptable range of solutions for $d$ and $p$ shown in Fig. 4 represent blurred images of the geoelectric profile beneath each site. The parameter pairs at each of the two bounds are the least probable results. If no additional constraints can be provided we are forced to accept the bounded intervals as depicted in Fig. 4. However, even with the parameter ranges obtained, it is clear that the depth to the HCL is unique to each location, and we have therefore established a genuine variation in depth $\mathrm{d}$.

If any one parameter of the $\mathrm{HCL}$ can be specified by, for example, geological or geophysical correlation, it is immediately apparent that we obtain almost unique estimates of the remaining parameters. For example, if the depth to a particular interface can be established independently, a much sharper geoelectric image can be obtained. Geological and geophysical correlations are therefore not merely a useful goal; they can ultimately provide quantitative enhancement of deep crustal images. The maximum acceptable resistivities found for the $\mathrm{HCL}$ at the three locations range from 18 to $55 \mathrm{ohm} \mathrm{m}$. This is not a large spread. A plausible constraint we apply next is to assume that the same physical mechanism is responsible for the HCL at the three locations---such an assumption for the deep crust appears reasonable, given our present degree of ignorance. Using Fig. 4 we then obtain an upper bound on the maximum resistivity at all three locations of $18 \mathrm{ohm}$. m. If such an assumption can be made, we successfully produce sharper images of the HCL at two of the three locations. The conductance $(a, t)$ values for the $\mathrm{HCL}$ would now range from 649-654 (MT1), 774-817 (MT2) and 858-1024 (MT3) Siemens, and we would have established much tighter bounds on the possible spatial geometries of the HCL.

The range of acceptable geometries of the $\mathrm{HCL}$ along a NW-SE profile through site MT2 is shown in Fig. 5. A wedge geometry, with a fiat base and dipping top, appears to be an unlikely configuration, but a NW-dipping layer or slab appears to be the most significant image. When interpreting this layer geologically it should be remembered that the central (best-fit) geometry is not the physically most likely solution, it is merely the model $(\mathrm{D}+)$ which produces the best-fit solution.

Earthquake fault-plane solutions

The 1979 Carlisle earthquake $\left(m_{b}=5.0\right.$; located in Fig. 1 ) aftershock sequence has been linked to the crustal structure of the lapetus suture (King 1980). A preliminary fault-plane solution apparently provided evidence for present-day N-S compression at shallow depth below the Solway-Carlisle Basin, within the Lower Palaeozoic. King suggested that the earthquake was a 'reactivation of planes 
of weakness broadly associated with' the lapetus suture. However, a more detailed new study now shows that the focal mechanism is more likely to have been mainly right-lateral slip on a vertical NW-SE trending fault zone (Marrow \& Roberts 1985). Aftershock hypocentres cluster between 4 and $8 \mathrm{~km}$ depth. This means, unfortunately, that the earthquake cannot now be considered to have any direct relevance to the lapetus suture as understood by us.

\section{Spatial Correlation}

The upper surface of the wedge of lower crustal reflectors on deep reflection profile WINCH-2E is interpreted as the trace of the lapetus suture (Brewer et al. 1983; Hall et al. 1984). Its apparent dip (i.e. in the plane of the section) is around $15-20^{\circ}$. The geoelectric profile, constructed by projecting the one-dimensional models for three stations onto a NW-trending vertical plane, then joining up the boundaries from station to station, independently gives a range of models for a conducting layer, dipping NW at $15-26^{\circ}$. In addition, the conducting wedge geometry, with a conductive lower crust wedging out to the north, appears to be unlikely, so that an identification of the lower, underthrust crust south of the suture, with high conductance does not appear to be feasible. Clearly, the geometric correlation of seismic and geoelectric profiles points to a physical model of a northdipping sheet or slab. Before we consider the physical basis of such a model, we can investigate the geometrical correlation further.

First, we can project the infinitely thin, (D+) layer (Fig. 5) onto WINCH-2E. For simplicity, we have done this by tying the depth to the D+ layer at the southernmost station MT3, $10.7 \mathrm{~km}$, to the top of the lower crustal layering on WINCH-2E at that depth, at about $58 \mathrm{~km}$ along the seismic profile. Stations MT2 and MT1 (depths 18.4 and $29 \mathrm{~km}$ respectively) are then projected along the same azimuth of $248^{\circ}$ onto WINCH-2E. Fig. 6a shows this correlation.

Second, we can project a finite-thickness conducting slab onto WINCH-2E in a similar manner to that described above. For the $10 \mathrm{ohm} \mathrm{m}$ resistivity layer used, we have chosen to identify the top of this layer with the top of the reflective wedge (Fig. 6b).

\section{Discussion}

The present study has considered two main sources of deep crustal information. We have attempted to correlate the structural boundaries resolved acoustically and electrically with due regard to the 3dimensional nature of the problem. One measure of structural definition is dip, and we have demonstrated very similar attitudes in the acoustic and electrical boundaries identified. The degree of equivalence supports the construction of depth contours shown in Fig. 6c, which necessarily assume linear continuity of structure. The geophysical images recognized presumably represent the vestigial trace of continental collision, which was completed during the late Silurian. The trace appears as a change in seismic reflective character approximately coincident with a zone of high electrical conductivity, which is of finite but unresolved thickness.

The pervasive nature of high electrical conductivity in the lower crust is now well-established (Shankland \& Ander 1983), and strong arguments exist for relating such zones to the presence of free fluids. In the 'dry' granitic crust considered by Olhoeft (1981) a resistivity of $10 \mathrm{ohm} \mathrm{m}$ cannot be achieved at temperatures below $1000{ }^{\circ} \mathrm{C}$; however the same resistivity is obtained for 'wet' granite with $1-2 \%$ water at a temperature of $250^{\circ} \mathrm{C}$. If such arguments are valid, the present 
electrical model requires a method for trapping and retaining fluids over the limited vertical geometry obtained. Models for the participation of metamorphic fluids in deep fault zones are now well- established for a number of crustal environments (Etheridge et al. 1983; Kerrich et al. 1984). It seems likely that deep thrust zones characteristically provide high permeability conduits for the focussing of substantial volumes of metamorphic hydrothermal fluids. Despite many other detailed arguments which must ultimately be considered, it seems that plausible mechanisms not only exist, but also predict that a zone of enhanced electrical conductivity will be associated with the final thrust surface of continental collision.

Since we have argued for continuity along strike of major crustal structure in support of our geophysical correlation discussed above (Fig. 6c), we now take this assumption as far as we dare, by constructing a single geological cross-section through the suture zone, trying to satisfy all the available data. This attempt is shown in Fig. 7. It should be considered merely as a sketch, and is not located precisely either on land through northern Britain, or offshore to the west. It serves to highlight the outstanding problems. The features of the cross-section are discussed below.

\section{The lapetus suture}

This is characterized by a band of reflections extending from $5 \mathrm{~km}$ depth to around $20 \mathrm{~km}$, and correlates with a highly conducting layer ( $\mathrm{HCL}$ ) a few kilometres thick. The HCL model (Fig. 5) suggests that the suture zone cuts the present-day Moho, rather than flattening out at the base of the crust. The suture at these depths can be interpreted as a shear zone of highly-conducting (?fluidfilled) mylonites and crush-rocks, dipping NW at $15-25^{\circ}$, and separating two continental crustal blocks. The zone may also correspond to the zone of steep velocity gradient on CSSP (Bott et al. 1985), recognized further NE along strike, which separates crust of $V P=6.15 \mathrm{~km} \mathrm{~s}^{-1}$ from lower crust of $\mathrm{VP}=6.6 \mathrm{~km} \mathrm{~s}^{-1}$ Continuation of the suture right up to outcrop using geophysical criteria is not feasible, since at shallow depth it represents the presumably complex collision line between two Lower Palaeozoic sedimentary packages. Neither of these are resolvable with present geophysical techniques, other than a characteristic P-wave velocity of the order of $5.0-5.7 \mathrm{~km} \mathrm{~s}^{-1}$

If the suture cuts through the Lower Palaeozoic at the same sort of angle as deeper down, and has possibly been reactivated as a low-angle normal fault underlying post-Caledonian sedimentary basins, then it may perhaps be taken more or less up to outcrop as suggested in Fig. 7. However, the shallow structure of the north of England and the Irish Sea cannot be represented adequately by a simple 2-dimensional cross-section, so this part of the picture is even more schematic than the rest. The south-dipping faults shown cutting the ?suture into segments here at 0-5 km depth is a schematic representation of structure interpreted from reprocessed versions of the corresponding part of WINCH-2E (our unpublished work).

\section{Sag basins above the suture zone}

The larger basin shown in Fig. 7 is a generalized picture of the Solway Basin, with the Northumberland Trough beneath. The smaller basin to the south could be, for example, the Peel Basin, west of the Isle of Man (see also Hall et al. 1984). The main basin, located in the hanging-wall of the suture, is up to $7 \mathrm{~km}$ thick, and filled with Carboniferous and Permo-Triassic sediments. The bottom of the basin is not easily mapped on existing seismic reflection data; however, we believe that it is probably more than twice as deep as the $2-3 \mathrm{~km}$ figure used by Bott et al. (1985) as control 
on their time-term modelling (note the depth of the basin shown in Fig. 3b \& 3c). This in turn implies that their depth to 'continental basement' is also likely to be underestimated. It is interesting to note that the basin is thickest, below the Solway Firth, above the area of the southward bulge in the suture contours shown in Fig. 6c. This suggests a locally greater amount of crustal extension here in a NW-SE direction, which has resulted, presumably, in both the development of the basin and the rise in the Moho beneath. A similar bulge is also seen in the aeromagnetic anomaly contours of the Solway Firth region.

\section{Lower Palaeozoic}

This appears to be characterized by an acoustically 'blank' sequence on all the currently available commercial reflection data in the offshore region. In fact the sequence is actually filled with a lot of shot-generated but incoherent signal, suggestive of complex reflection paths, reflected refractions, etc. which is very different from the acoustically transparent upper crust as seen, for example on the WINCH data from the Lewisian foreland (Brewer \& Smythe 1986). However, we describe it here as 'blank', since no structural image can be interpreted from it. The Carlisle earthquake hypocentre is placed within the Lower Palaeozoic 'blank' sequence at a nominal depth of $5 \mathrm{~km}$ (CEQ in Fig. 7).

Our interpretation puts the Manx Slates of the Isle of Man (Fig. 1) above and to the north (in the hanging wall) of the suture, since the approximate $5 \mathrm{~km}$ depth contour runs across the island (Fig. $6 \mathrm{c})$. These rocks are of Atlantic, or Baltic, affinity, and therefore might be thought to 'belong' to the crust on the south side (the foot wall) of the suture. This apparent discrepancy demonstrates the difference between the geophysically defined suture, which cuts the continental basement, and the geologically defined lineament in the Lower Palaeozoic cover, discussed above. Presumably the cover is in part allochthonous, having been scraped off a subducting passive margin during the final stages of collision.

The Lower Palaeozoic sequence in the Southern Uplands has a P-wave velocity of 5.0-5.6 km s-1 as measured at outcrop and down to $5 \mathrm{~km}$ (Hall et al. 1983). Since velocities in excess of $6.0 \mathrm{~km}$ are associated with granite-like rocks, and preclude Lower Palaeozoic greywacke facies, the VP= $6.15 \mathrm{~km}$ phase observed in the Irish Sea on CSSP has been interpreted by Bott et al. (1985) as continental basement below a thin Lower Palaeozoic sequence. They assume that the basement phase is from the south side of the suture (Bott et al. 1985, fig. 4a). We suggest, however, that the

Solway Firth continental crust phase $\left(V_{p}=6.15 \mathrm{~km} \mathrm{~s}^{-1}\right)$ comes from the south-dipping reflective layered zone above (i.e. north of) the suture (Fig. 1). This interpretation assumes that the seismically 'blank' zones below the basins correspond to Lower Palaeozoic, and also implies that Bott et al.'s interpretation of the upper crustal structure below the Solway Basin segment of CSSP is all too shallow by a factor of two, as we have already pointed out appears to be the case for the sedimentary cover. It also leads to a potentially useful correlation of seismically layered crust northwards into the Southern Uplands, as suggested in Fig. 7.

\section{Crust south of the suture}

The lower crust is seismically well layered between 12 and $22 \mathrm{~km}$ depth, with a suggestion of consistent southerly dips. This is particularly well seen on WINCH-3, where the X4 vertically exaggerated reproduction of the data in Fig. 2 roughly cancels out the obliquity with which the line crosses the structure (Fig. 6c). There is also a tenuous suggestion from the data (Fig. 2) that the 
lower crust about $5 \mathrm{~km}$ above the Moho makes a distinct band of reflectors; this has been depicted schematically in Fig. 7

\section{Crust north of the suture}

We have extrapolated northwards the south-dipping reflective layering seen on the commercial profiles in the northern Irish Sea, on the assumption that it will also characterize the crust of VP= $6.1 \mathrm{~km}$ found at shallow depth below the Southern Uplands (Hall et al. 1983). However, below the Southern Uplands we have depicted speculatively a herring-bone pattern of layering, to allow for the possible presence of both north-dipping and south- dipping structure. Perhaps there is a small-scale version here of the whole-crustal 'zig-zag' shortening model proposed by Hall et al. (1984). The almost complete lack of layering of the crust on WINCH-2 (Figs. 2, 6a) here is due partly to the unfavourable local conditions in the North Channel, where the shallow Upper Palaeozoic sediments are cut by numerous Tertiary intrusions. How the Southern Uplands crustal structure continues northwards below the Southern Uplands fault into the Midland Valley is unclear. On Fig. 7 the seismic velocities and layers are taken from the LISPB line (Bamford et al. 1978) and more recent refraction work (Davidson et al. 1984).

\section{Conclusions}

The lapetus suture is probably the most fundamental tectonic lineament crossing the British Isles and Ireland. We have shown how the two most powerful methods of imaging the crust--deep seismic reflection and geoelectric sounding-independently suggest the presence of a major northdipping interface or slab below the region of the suture. We have correlated the two experiments both with each other and with the surface geology along strike for a distance of some $200 \mathrm{~km}$. However, we are well aware that we risk correlating the invisible (the 'upper edge' of some seismic reflective layering) with the impossible (a highly conducting layer of zero thickness), and with the imaginary (the geological cartoons of what a continental collision zone should look like)! Nevertheless, we conclude that our two methods, particularly in conjunction with each other, offer the most powerful means available of testing the geological hypotheses of crustal collision in the Caledonides.

We also conclude that the major crustal seismic refraction type of experiment like LISPB and CSSP can only be an ancillary tool where, as in the case of the lapetus suture, the lateral spatial variation of structure is on the same scale as the vertical variation. We would also emphasize the importance of orthodox multichannel seismic reflection data (shot to $6 \mathrm{~s}$, or about $15 \mathrm{~km}$ of potential penetration) in providing the detailed control necessary on the upper crustal structure for successfully locating, processing and interpreting the whole-crustal experiments.

\section{Acknowledgements}

We are particularly grateful to Bernard Raynaud of Cambridge University for allowing us to copy his ray-tracing migration program for use on deep crustal reflection data. We also thank Bob Parker of the University of California for providing the original coding of his algorithms. Western Geophysical Company of America kindly permitted the reproduction of line drawings of their proprietary seismic reflection data. Lastly we thank our colleagues Phil Mulholland, lan Jackson and Fred Dunning for useful discussions on Irish Sea and Caledonian geology, and the reviewers Drum Matthews, Jeremy 
Hall and Roger Banks for their constructive comments. Calum Ritchie drew the diagrams. The contribution of one of us (DKS) is funded by the Department of Energy. The paper is published by permission of the Director, British Geological Survey (NERC).

\section{References}

BACKUS, G.\& GILBERT,F. 1968. The resolving power of gross Earth data. Geophysical Journal of the Royal Astronomical Society, 16,169-205.

$-\&-1970$. Uniqueness in the inversion of inaccurate gross Earth data. Philosophical Transactions of the Royal Society, AM, 123-92.

BAMFORD,D., FABER, S., JACOB, B., KAMINSKI, C., W., NUNN, K. PRODEHL, FUCHS, K., KING, R.\& WILLMORE, P. 1976. A lithospheric seismic profile in Britain-I. Preliminary results. Geophysical Journal of the Royal Astronomical Society, 44, 145-60.

-, NW, K., PRODEHL,C. \& JACOB,B. 1978. LISPB-IV. Crustal structure of northern Britain. Geophysical Journal of the Royal Astronomical Society, 54, 43-60.

BEAMISH, D. 1986a. Deep crustal geoelectric structure beneath the Northumherland Basin. Geophysical Journal of the Royal Astronomical Society, 84,619-40.

-, 19866. Geoelectric structural dimensions from magnetotelluric data: methods of estimation, old and new. Geophysics, 51 (in press).

BOTT, M. H. P., LONG, R. E., GREEN, A. S. P,, LEWIS, A. H. J., SINHA,M. C. \& SEVENSON, D. L. 1985. Crustal structure south of the lapetus suture beneath northern England. Nature, 314, 724-7.

BREWER, J. A., MATTHEWS, D. H., WARNER,R., HALL,M. J., SHYTHE,D. K. \& WHITTINGTON, R. J. 1983. BIRPS deep seismic reflection studies of the British Caledonides. Nature, 305, 206-10.

-\& SMYTHE, D. K. Deep structure of the foreland to the Caledonian orogen, NW Scotland: results of the BIRPS WINCH profile. Tectonics, 5 (in press).

DAVIDSON,K. A. S., SOLA,M,, POWELL, D. W. \& HALL, J. 1984. Geophysical model for the Midland Valley of Scotland. Transactions of the Royal Society of Edinburgh: Earth Sciences, 15, 175-81.

ETHERIDGE, M.A., WALL, V.J. \& VERNON, R. H.1983. The role of the fluid phase during regional metamorphism and deformation. Journal of Metamorphic Geology, 1, 205-6.

HALL,J., BREWER,J. A., MATIHEWS, D. H. \& WARNER,M. R. 1984. Crustal structure across the Caledonides from the 'WINCH' seismic reflection profile: influences on the evolution of the Midland Valley of Scotland. Transactions of the Royal Society of Edinburgh: Earth Sciences, 15, 97-109.

-, POWELL, M. W., EL-ISA,Z. H. M, ADESANYA, D. W., WARNER, 0.\& BLUCK,B. J. 1983. Seismological evidence for shallow crystalline basement in the Southern Uplands of Scotland. Nature, 305, 418-20.

KERRICH, R.,LA TOUR, T. E. \& WILLMORE, L. 1984. Fluid participation in deep fault zones: evidence from geological, geochemical and 180/'60 relations. Journal of Geophysical Research, 89, 4331-43. 
KING, G. 1980. A fault plane solution for the Carlisle earthquake, 26 December 1979. Nature, 286, $142-3$

LEGGET, J. K., MCKERROW, W. S. \& EALES,M.H. 1979. The Southern Uplands of Scotland: a Lower Palaeozoic accretionary prism. Journal of the Geological Society, London, 136,755-70.

MARRROW, P. C. \& ROBERTS, G. 1985. Focal mechanism of aftershocks of the 1979 Carlisle earthquake: a re-interpretation. Geophysical Journal of the Royal Astronomical Society, 83, 797-802. MOSELEY, F. 1977. Caledonian plate tectonics and the place of the English Lake District. Bulletin of the Geological Society of America, 88, 764-8.

OLHOEFT, G. R. 1981. Electrical properties of granite with implications for the lower crust. Journal of Geophysical Research, 86, 931-6.

PARKER, R.L. 1980. The inverse problem of electromagnetic induction: existence and construction of solutions based on incomplete data. Journal of Geophysical Research, 85, 4421-5.

-1983. The magnetotelluric inverse problem. Geophysical Surveys, 6, 5-24.

-\& WHALER,K. A. 1981. Numerical methods for establishing solutions to the inverse problem of electromagnetic induction. Journal of Geophysical Research, 86, 9574-84.

PHILLIPS, C. J. \& MURPHY, T., W. E. A., STILLMAN, 1976. A Caledonian plate tectonic model. Journal of the Geological Society of London, 132, 579-609.

SHANKLAND, J. \& ANDER, M. E. 1983. Electrical conductivity, temperatures and fluids in the lower crust. Journal of Geophysical Research, 88, 9475-84.

THOMPSON, B. G., NEKUT, A. \& KUCKES, A. F. 1983. A deep crustal electromagnetic sounding in the Georgia Piedmont. Journal of Geophysical Research, 88, 9461-73.

WILSON, J. T. 1966.Did the Atlantic close and then re-open? Nature, 211, 676-81. 


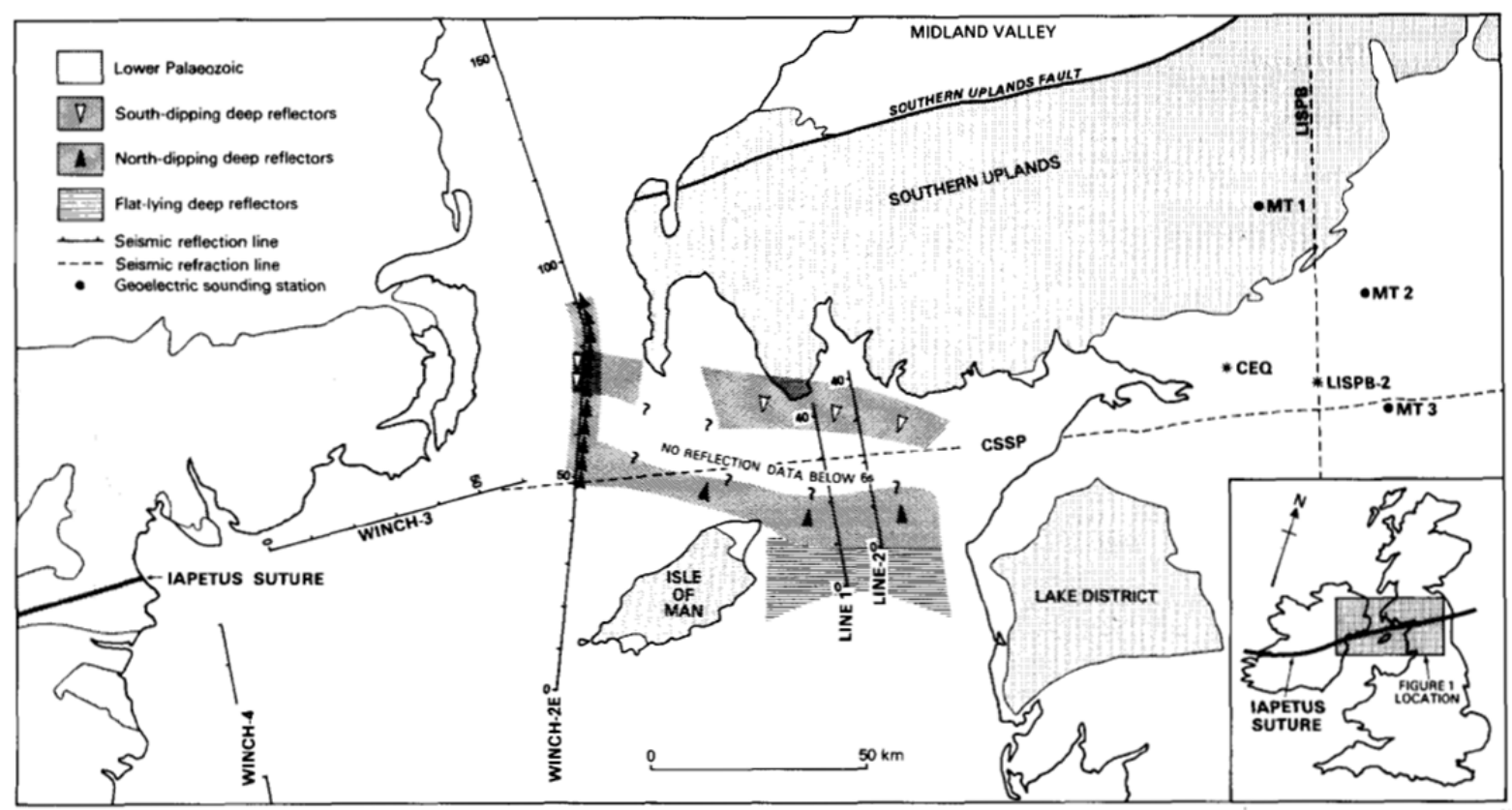

Figure 1 Location map of the detailed geophysical experiments pertaining to the structure of the lapetus suture through the region (located on the inset). Tick marks on seismic reflection profiles are $10 \mathrm{~km}$ apart LISPB-Lithospheric seismic profile of Britain; LISPB-2 is one of its main shots. CSSP-Caledonian suture seismic project. WINCH-Western Isles-North Channel line. The position of the lapetus suture in NE Ireland is taken from Phillips et al. (1976). CEQ-1979 Carlisle earthquake epicentre 

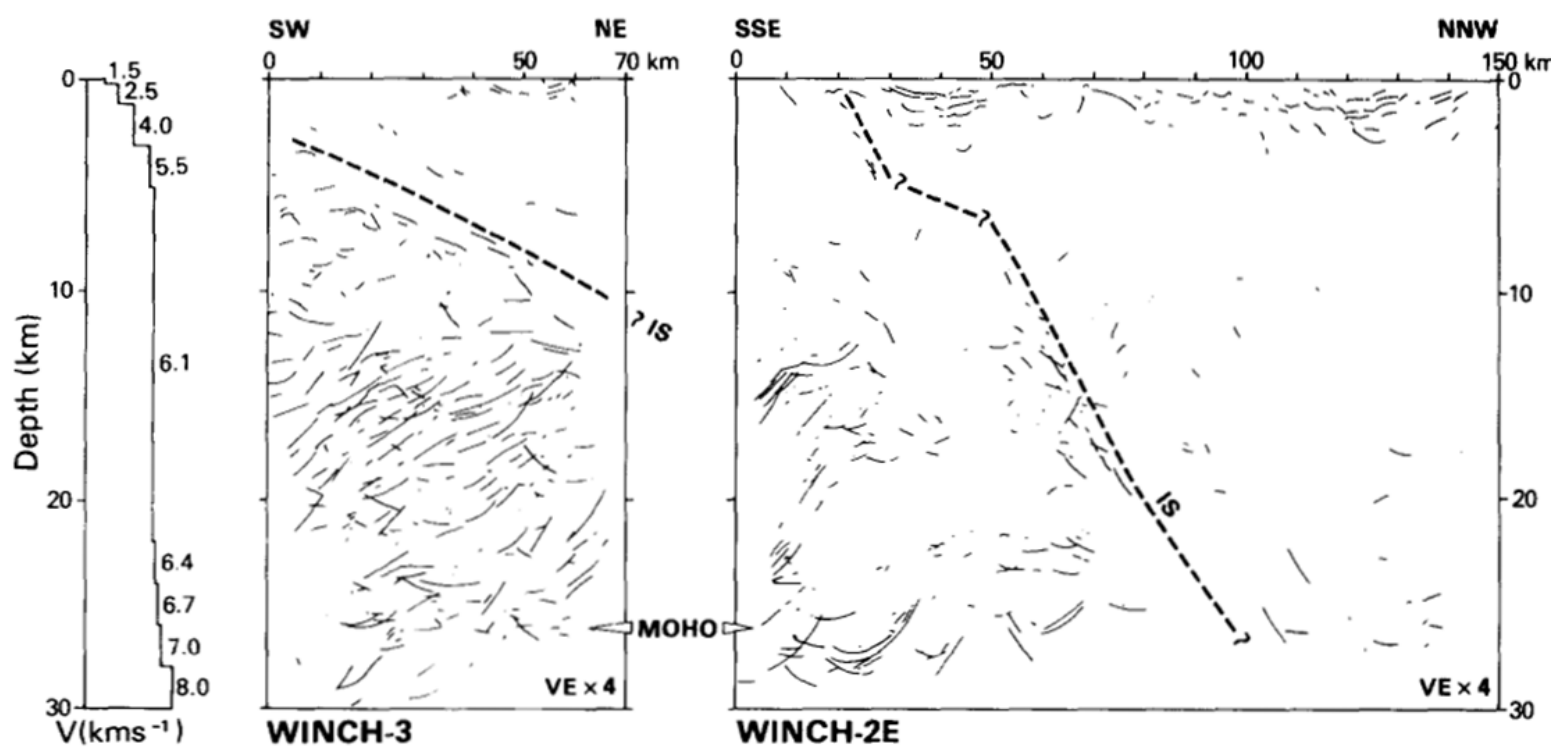

Figure 2 Depth-migrated line drawings of WINCH-2E and WINCH-3 (located in Fig. 1), using the 1-dimensional velocity function shown at the left-hand side. IS (dashed line)--conjectural trace of the lapetus suture, separating seismically well-layered crust to the south from relatively unlayered crust to the north. Record section (i.e. unmigrated) linedrawing data input to the migration program is the same as that reproduced by Brewer et al. (1983). The portion of the stacked section of WINCH-2E from 34-94 km showing the suture has been published by Hall et al. (1984). All 'smiles'migrated reflector segments which have reflector raypaths crossing below $0 \mathrm{~km}$ depth-have been omitted from the depth-migrated plots, as they tend in practice not to have originated from deep structure. 


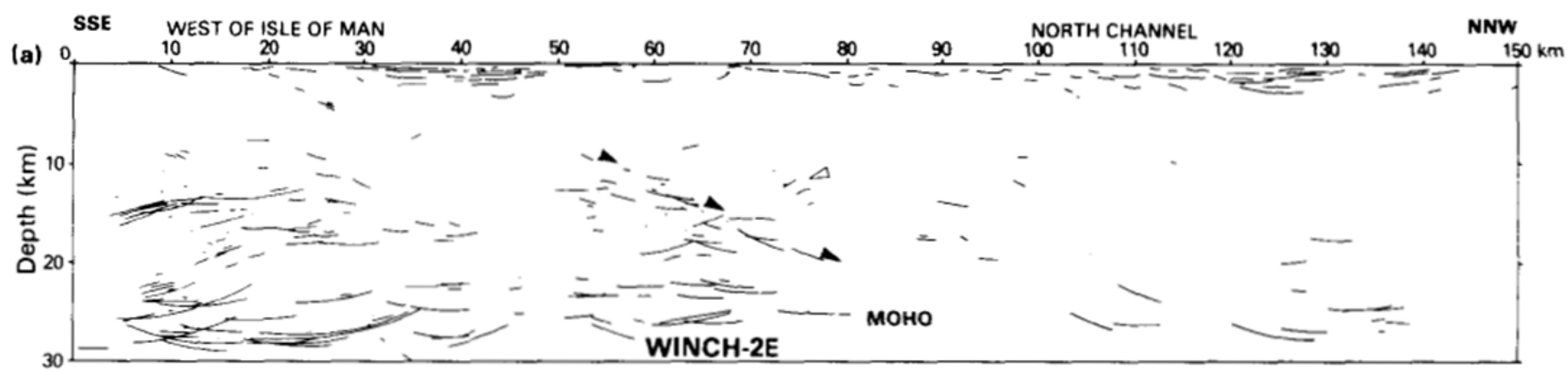

No vertical exaggeration

- North-dipping reflectors

$\triangle$ South-dipping reflectors

SB Solway Basin

LP Lower Palaeozoic outcrop
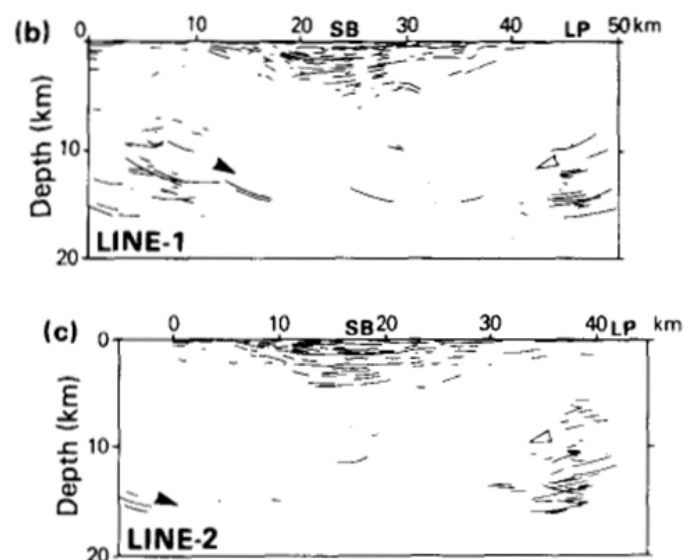

Figure 3 Depth-migrated line drawings of seismic reflection sections (located in Fig. 1): (a) WINCH-2E; same data as in Fig. 2, but with no vertical exaggeration. (b) Line-1, interpreted from a proprietary stacked seismic section shot to $6 \mathrm{~s}$ (two-way time). The migration shows that the south-dipping reflectors at the right-hand side, recorded offshore, originate from below the landward outcrop of the Lower Palaeozoic (LP)--see Fig. 1-permitting its correlation with the acoustically 'blank' sequence below the Solway Basin (SB). (c) Line-2, as for Line-1; this is the best example of the southdipping reflector group (see text for discussion). However, it does not display the north-dipping reflectors, which have been mapped at this locality and some $15 \mathrm{~km}$ further east using other data (see Figs 1 \& 6). 


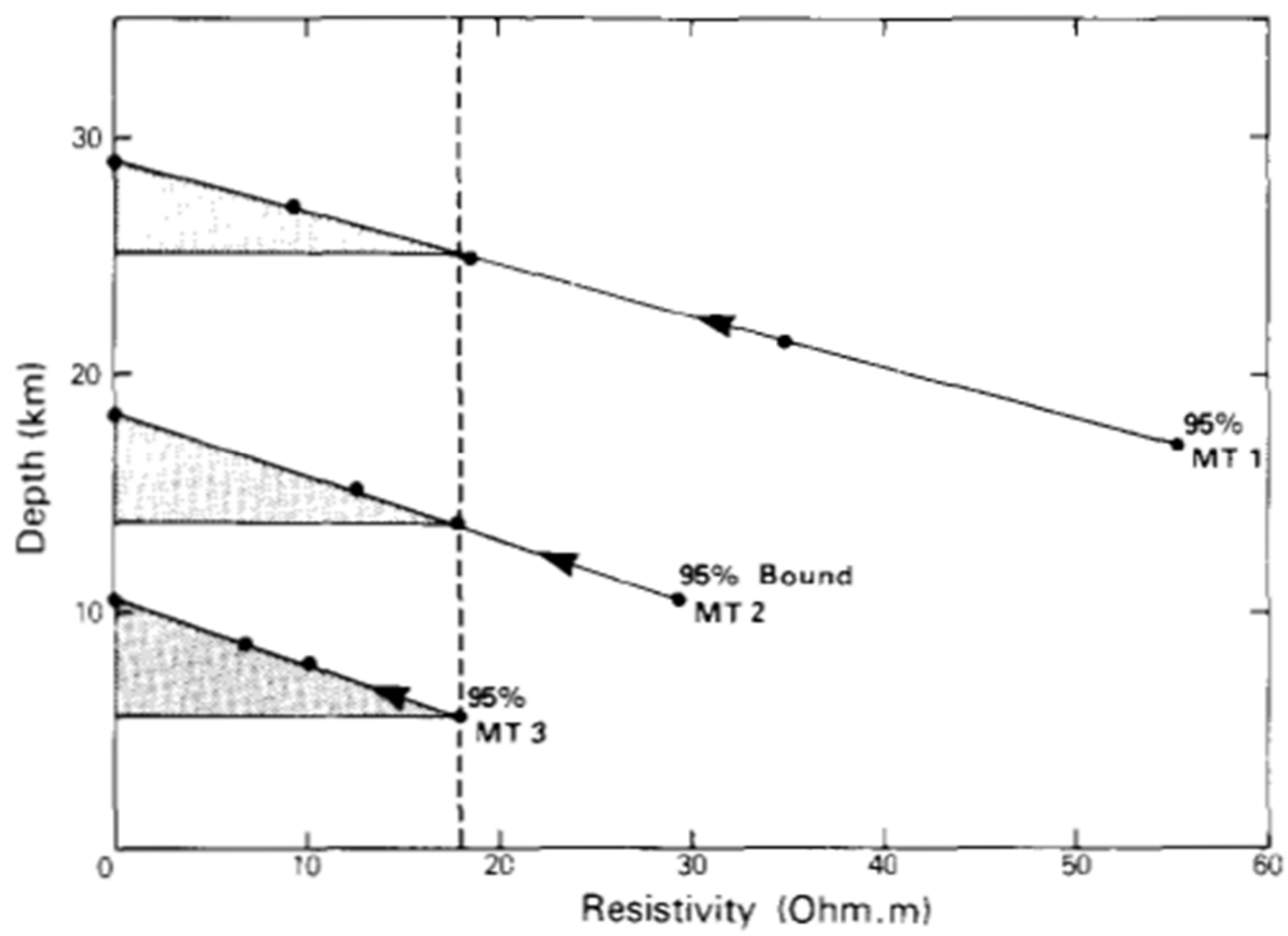

Figure 4 Families of acceptable estimates (solid lines) of the depth to, and resistivity of, the highly conducting layer ( $\mathrm{HCL})$, at the three sites MT1, MT2 and MT3. Arrows indicate direction of decreasing misfit. Shaded regions below 18 ohm $\mathrm{m}$ display ranges of acceptable estimates if we assume the same resistivity occurs at all three locations. 


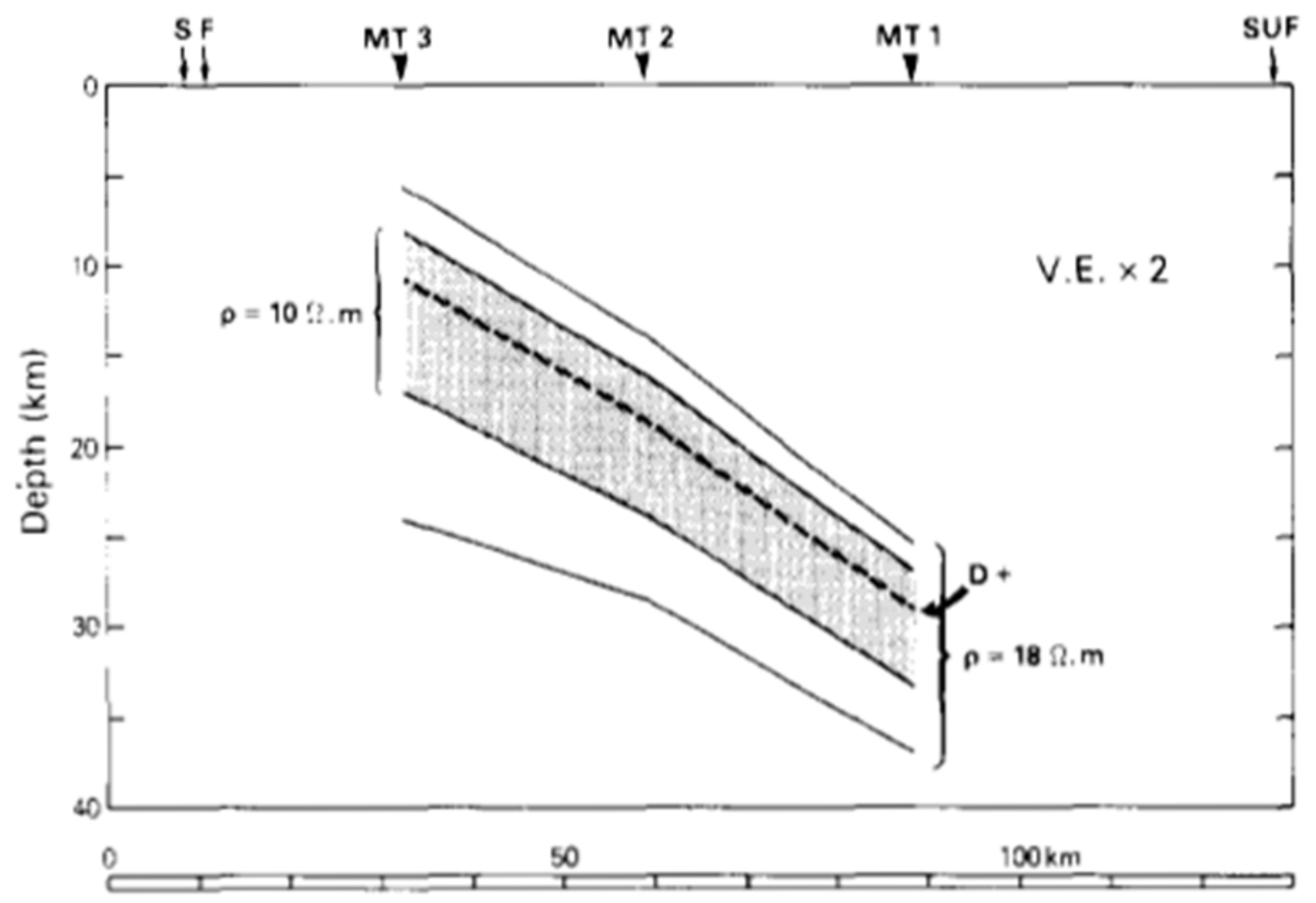

Figure 5 Acceptable geometries of the highly conducting layer plotted on a profile $45^{\circ}$ west of grid north and passing through site MT2. Vertical exaggeration $\times 2$. D+, possessing zero thickness, is shown as a dashed line. Two layers of resistivities 10 and $180 \mathrm{hm} \mathrm{m}$ are stippled. SF, Stublick faults; SUF, Southern Uplands fault. 

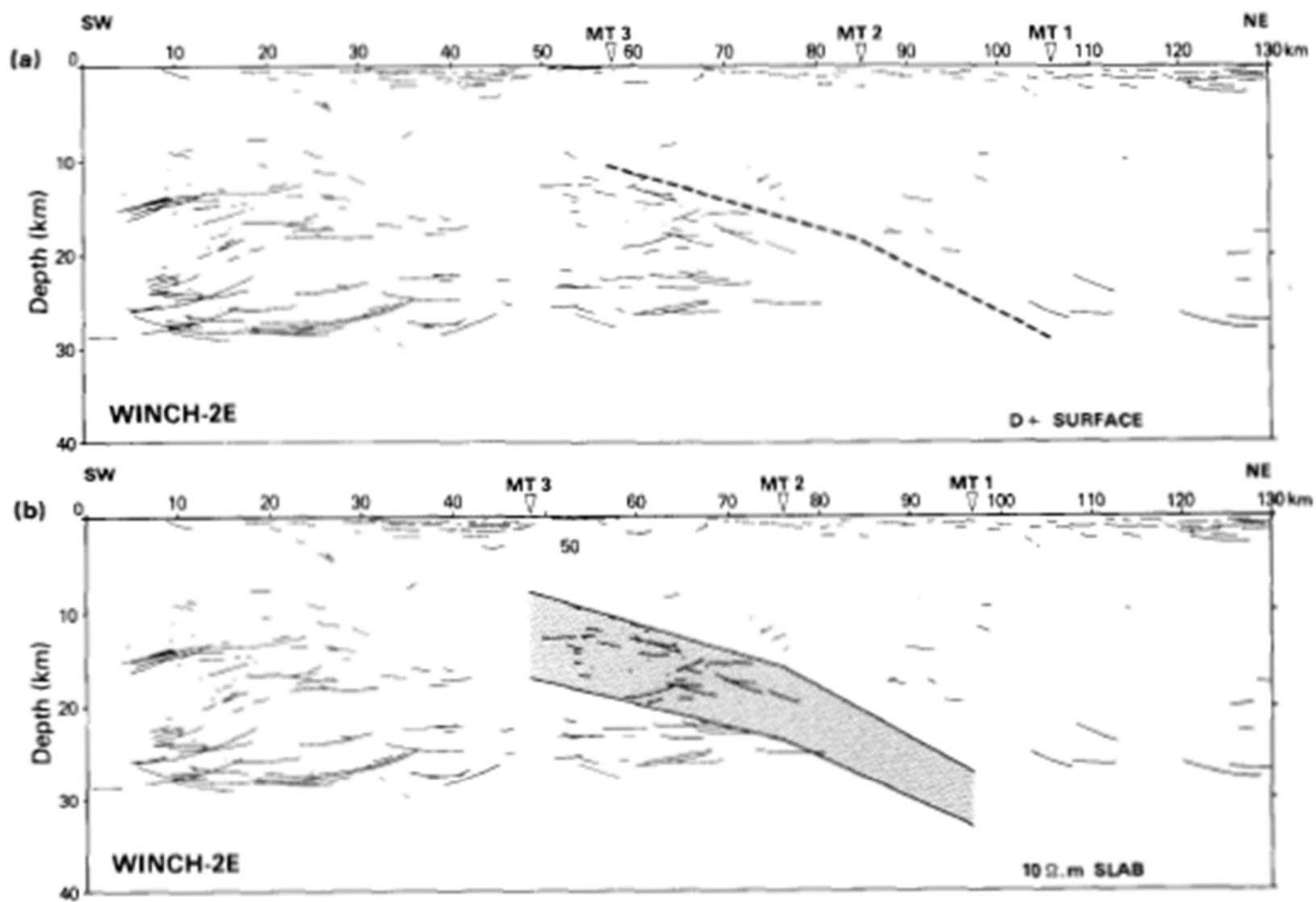

(c)

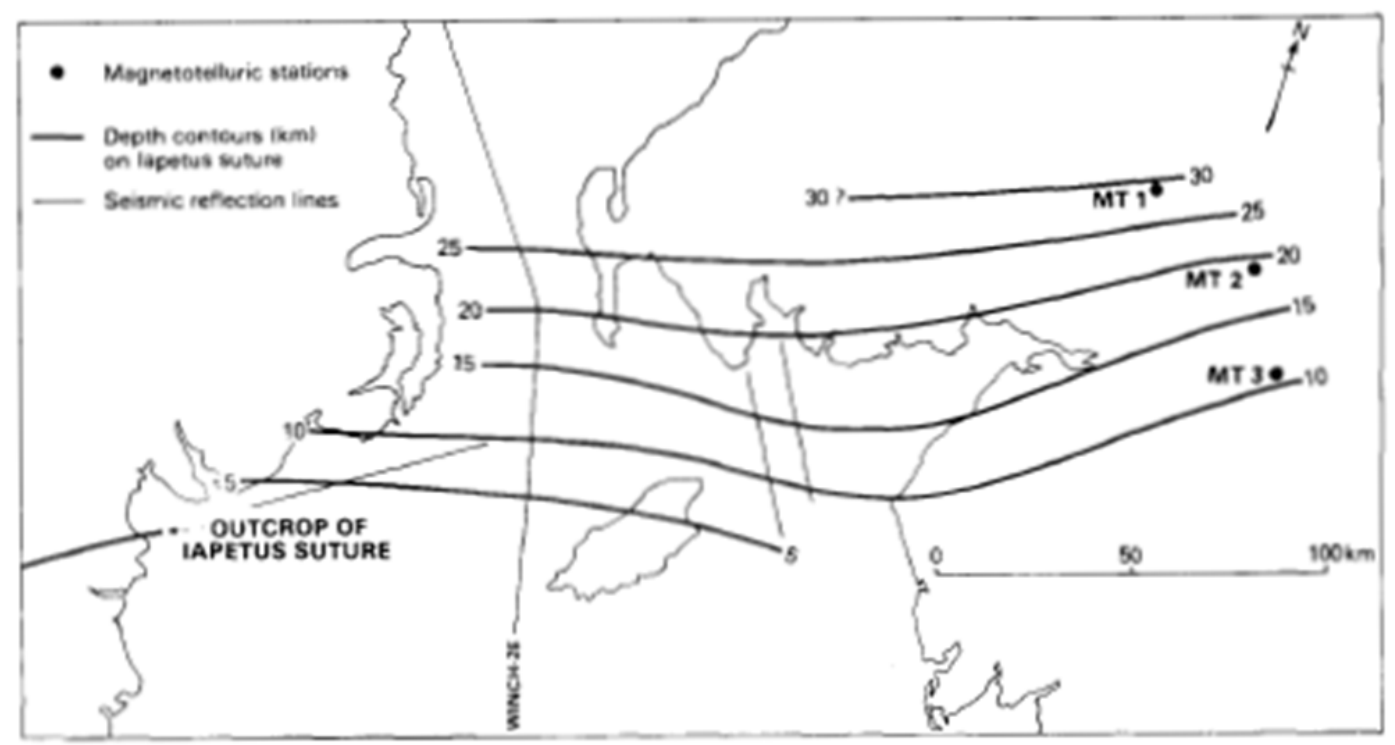

Figure 6 Correlation of seismic and electrical images (a) Migrated depth section from WINCH-2E and electrical D+ image of zero thickness (dashed line). No vertical exaggeration. See text for details. (b) As for (a), but using electrical $\mathrm{H}+$ layer model of resistivity $10 \mathrm{ohm} . \mathrm{m}$ (stippled area). (c) Depth contours on the lapetus suture resulting from correlation of the seismic and electrical north-dipping surfaces. Note that the southward bulge of the contours in the Solway region corresponds to the area of maximum thickness of the overlying Solway Basin. This may he a new example of the now commonplace relationship between crustal stretching and basin formation 


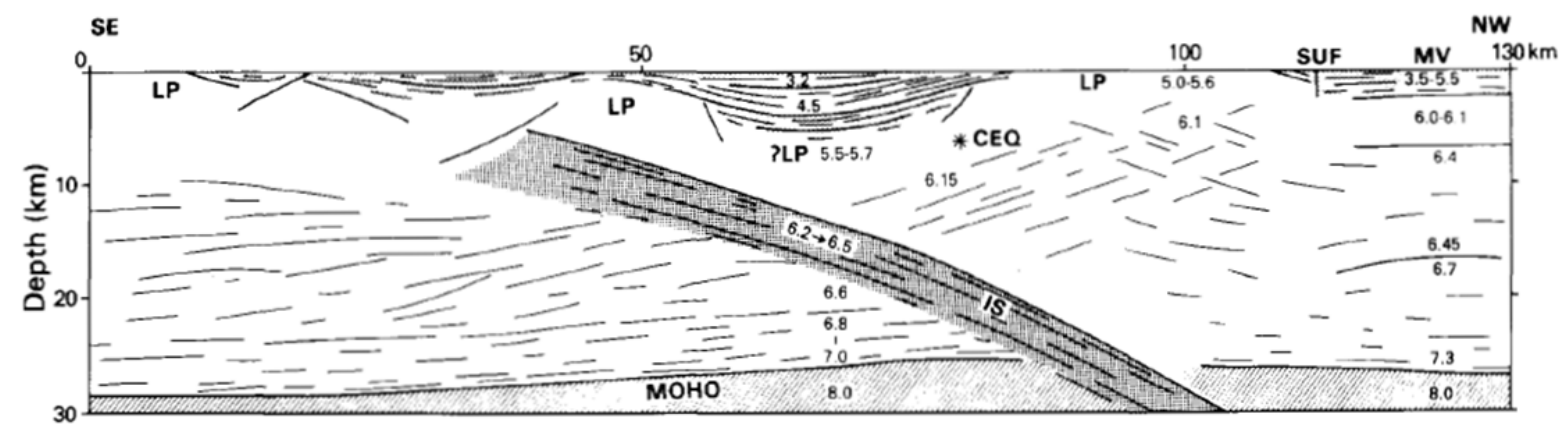

Figure 7 Speculative geological cross-section through the region of the lapetus suture (IS) where the experiments shown in Fig. 1 are clustered, assuming a large degree of 2-dimensional continuity along $\mathbf{2 0 0} \mathbf{~ k m}$ of strike. It is loosely based on deep seismic reflection structure, with the addition of P-wave velocities $\left(\mathrm{km} \mathrm{s}^{-1}\right.$ from the various refraction experiments- see text for discussion. Bold stippled area represents the highly conducting layer (HCL), which has resistivity of the order of 1-20 ohm m. Light stipple, Upper Palaeozoic sediments. LP, Lower Palaeozoic; CEQ, schematic hypocentre of the Carlisle earthquake (see text); SUF, Southern Uplands fault; MV, Midland Valley. 